\title{
LA ORIENTACIÓN FAMILIAR: UNA EXPERIENCIA DE INTERVENCIÓN
}

\author{
Cecilia Villarreal Montoya \\ Directora del Posgrado en Orientación en la Facultad de Educación y \\ docente de la Escuela de Orientación y Educación Especial. \\ Universidad de Costa Rica \\ San José, Costa Rica
}

Recibido 8-X-2007 • Aceptado 13-XI-2007 • Corregido 12-III-2008

\begin{abstract}
Resumen: El artículo resume la experiencia de intervención con una familia de la escuela de Villa Esperanza de Pavas. Se trata de un matrimonio con dificultades para disciplinar a sus tres hijos varones de ocho, seis, y cuatro años.

En primer lugar, se exponen los principios teóricos y metodológicos, para luego mostrar la aplicación de ellos en el proceso vivido por la familia. Se aplica el modelo de intervención estructural, que busca que la misma familia logre realizar, paso a paso, los cambios requeridos en la dinámica y estructura familiar. En la situación específica de esta familia, se observa el fortalecimiento de la pareja como tal y como madre y padre en la medida que van logrando asumir la autoridad en forma compartida para disciplinar a los hijos.

Al compartir esta experiencia, la autora pretende estimular a profesionales en Orientación a asumir el reto de considerar a las familias de la comunidad estudiantil, de las instituciones educativas donde laboran, como parte importante en el quehacer orientador.
\end{abstract}

Palabras claves: Orientación familiar, terapia de familia, educación parental.

\section{Introducción}

La comunidad de profesionales en Orientación reconoce el impacto que tiene la familia en el crecimiento y desarrollo de las personas. Sin embargo, en el ejercicio profesional la tendencia ha sido planear y realizar programas y proyectos de orientación personal, educativa y vocacional-profesional sin tomar en cuenta a las familias de la población infantil y adolescente de las instituciones educativas del país.

Tanto la familia como el centro educativo comparten la gran responsabilidad de la educación, la formación y el desarrollo humano de la población del país. El debate se ha centrado en cómo lograr la coordinación entre ambas instancias y la pregunta eje sigue siendo: ¿de qué manera pueden familia y escuela colaborar entre sí en la ardua tarea de educar? plantea Jaramillo (2002). El trabajo conjunto entre ambas instituciones sociales requiere ser planificada, no debe dejarse a la espontaneidad u ocurrencia de ambas partes. Hay que partir de que la relación siempre se va a dar, no es posible obviar el hecho de 


\begin{abstract}
This article summarizes the experience of the intervention with a student's family at the Villa Esperanza de Pavas school. It involves a marriage with difficulty disciplining their three boys, who were eight, six, and four years old respectively.

First, we present the theoretical and methodological principles, then how they were applied in the process with this family. The approach applied was the structural intervention, seeking to help the family attain, step by step, the changes required by family dynamics and structure. In this family's specific situation, the process strengthened the couple, both as a couple and as father and mother, as they gradually undertook a shared authority to discipline their children.

By sharing this experience, the author seeks to urge Counselors to undertake the challenge of considering the families of their student community, at the educational institutions where they work, as an important part of the counseling process.
\end{abstract}

Key words: Family counseling, family therapy, parent education. que lo que se realice en el centro educativo formará parte de la convivencia familiar y viceversa, porque ambos sistemas se influyen mutuamente.

$\mathrm{Al}$ no establecerse formas y mecanismos de coordinación se puede caer en una interacción no propicia para la comunidad estudiantil, como el interjuego de culpabilización mutua, "cultivar esta actitud trae consigo el inconveniente de que cuando surge una dificultad se asume una posición defensiva, se fija la atención en las fallas del otro y se cierra el camino a la autocrítica" apunta Jaramillo (2002, p. XV), afectándose la eficacia del trabajo colaborativo.

Para coordinar la acción educativa entre familia y centro educativo, se requiere de la definición de políticas claras en la institución educativa; además de la aplicación de éstas en actividades concretas de intervención con las familias. Con un posicionamiento así, la atención a las familias se convierte en un pilar de trabajo de los departamentos de Orientación. La labor con las familias no se puede evadir, especialmente cuando la acción orientadora, dirigida a infantes, adolescentes, personas adultas, y mayores se enmarca dentro de la perspectiva del desarrollo humano integrado.

Este artículo tiene como propósito compartir una experiencia de intervención directa con una familia, como una de las tantas formas de realizar el trabajo con familias en los centros educativos. Además, el interés es aportar un nuevo insumo al debate nacional, sobre la labor social del sistema educativo para con las familias en general y sobre la misión y posicionamiento de la Orientación y el de sus profesionales respecto al quehacer orientador con las familias de la comunidad estudiantil, en particular.

Lo peculiar de la experiencia que presento, es el hecho de que la situación pudo haberse atendido en el centro educativo, ya que se originó allí: al observarse la conducta agresiva de un estudiante de kindergarten, la maestra envió al niño a un centro de salud apelando a la necesidad de que fuera medicado, bajo la hipótesis de que éste pre- 
sentaba déficit de atención. El proceder de la docente muestra una tendencia, primero, al deficiente trabajo en equipo en la institución y de ésta con la familia, para favorecer el desarrollo integrado de sus estudiantes, y en segundo lugar, a estigmatizar las conductas del niño, en este caso, evitando explorar la situación concreta de éste. Para comprender la realidad del estudiante, se requiere necesariamente un acercamiento con la familia de éste.

\section{Posicionamiento teórico}

Según Nugent (1990), en los Estados Unidos el término orientación familiar se utiliza exclusivamente en los centros educativos públicos, para denominar el trabajo que realizan profesionales en Orientación con familias que experimentan lo que él llama problemas normales. Para este mismo autor, no existe diferencia entre Terapia de familia y Orientación familiar. Plantea que ambas utilizan la misma base teórica, las técnicas y los procedimientos, y además cumplen los mismos objetivos.

En los centros educativos, la Orientación familiar se puede implementar a diversos niveles: desde realizar una gran diversidad y modalidad de programas dirigidos a la formación y al desarrollo de habilidades básicas para el alcance de las tareas en la convivencia familiar y para el cumplimiento de los roles conyugal, maternal, paternal y filial de hombres y mujeres de diferentes edades; hasta intervenir directamente a las familias que lo requieran.

Para ofrecer la Orientación familiar es necesario moverse de un posicionamiento teórico y metodológico centrado en la persona en sí misma para verla como un ser en interacción. Esta perspectiva se viene desarrollando desde mediados del siglo XX y ha ido conformando una base teórica $\mathrm{y}$ epistemológica sobre la convivencia relacional, se parte del principio que las personas se influyen entre sí, construyéndose de esta forma redes humanas que permiten expli- car, comprender y transformar las interacciones individuales y colectivas.

El posicionamiento sistémico-estructural, como parte de ese cuerpo del conocimiento, concibe a la familia como "un sistema social en transformación" Minuchin (1985, p. 27) integrado por "un grupo de personas, unidas emocionalmente y o por lazos de sangre, que han vivido juntos el tiempo suficiente como para haber desarrollado patrones de interacción e historias que justifican y explican tales patrones" (Minuchin, Lee, y Simon, 1998, p. 47). Además, "los problemas y las conductas sintomáticas de las personas son concebidas como el resultado de las interacciones inadecuadas al interior de la familia, en donde cada quien es parte, y no como un conflicto individual intrasíquico" plantea Sturges, citado por Ronch, Van, y Stilwell (2006, p. 359).

Los sistemas complejos se componen de subsistemas, cada persona es un subsistema en sí mismo y participa en subsistemas dentro del sistema familiar. Según el tipo de familia así será la formación de los subsistemas, si se trata de una familia nuclear heterosexual y con descendencia se identifican los siguientes: conyugal (esposa-esposo/compañero-compañera); parental (madre y padre con la prole); fraternal o filial (hermanos y hermanas); extendido (abuelos, abuelas, otros parientes); el subsistema de mujeres (las que integran la familia); y el subsistema de los hombres.

Otro criterio clave dentro de la perspectiva sistémica relacional es el hecho de que "los subsistemas dentro de un sistema más amplio, están perfectamente delimitados, y las interacciones entre compartimientos están gobernados por conductas y reglas implícitas" (Musitu, Román y Gutiérrez, 1996, p. 35). Las relaciones entre las personas se enmarcan por los límites o las fronteras, éstas se definen tanto por "las expectativas acerca de cómo deben conducirse las personas en diversos tipos de ambientes y circunstancias" (Richardson 1993 , p. 28), como por las reglas de convivencia, las costumbres, los valores y los 
intercambios afectivos constantes. Barylko (2005), lo resume como el afecto, la seguridad y el compromiso en la expresión del cuidado, la atención de las necesidades y las relaciones de confianza entre los subsistemas. En sus propias palabras, Barylko (2005, p. 60), afirma, "Si hablo de límites hablo de amor, de relación, de ser con otros".

Lo adecuado es que los límites y las reglas vayan cambiando y flexibilizándose en la medida en que la familia vaya avanzando en su ciclo vital. Los sistemas familiares viven en constante cambio debido al propio desarrollo de los subsistemas y del sistema mismo, y aunque tengan la capacidad de auto-organizarse, y autorregularse no pueden concebirse en términos del equilibrio completo, de la predeterminación, del control jerárquico, de la permanencia o de la predictibilidad estructural. Según Hernández (1998) hay que tomar muy en cuenta la condición humana de las familias y por eso mismo es que hay que reconocer la imperfección, la inestabilidad, la incertidumbre, la diferenciación y la ecodependencia entre los subsistemas como condiciones de los procesos y de las estructuras familiares.

Los sistemas familiares se construyen y reconstruyen constantemente; lo anterior se da por la capacidad que tienen para evaluar la propia dinámica y replantearla basada en los efectos de sus propias interacciones (Suares, 2002). Una mayor disposición al cambio permite el crecimiento y desarrollo del sistema familiar, mientras que la oposición o resistencia a éste, pone al sistema en riesgo. Cuando el sistema se encuentra en esta última posición enfrenta problemas o dificultades en el desarrollo de cada uno de los subsistemas, esto por cuanto la familia es una totalidad y los diferentes subsistemas se influyen mutuamente. Estas son las condiciones que generalmente lanzan a las familias a la búsqueda de ayuda profesional.

La comunicación cumple un papel esencial en los procesos de relación y cambios en los sistemas familiares, por el hecho de que toda conducta es comunicación, es imposible no comunicarse, y el comportamiento de una persona tiene valor de mensaje para las demás, plantea Watzlawick y otros (1983). Para este mismo autor, se le debe dar igual importancia a los mensajes verbales como a los no verbales, al tipo de relación y a los contenidos que se intercambian, a la forma en que se puntúa en las secuencias de interacciones, y a las relaciones basadas en la igualdad o diferencia, o sea, la interacción simétrica o complementaria entre las personas.

\section{Valoración del sistema familiar}

Para identificar y comprender la estructura de un sistema familiar es necesario observarlo estando éste en plena acción. Al evaluar una familia, tanto Minuchin (1985) como Whitaker y otros (1991), coinciden en que la atención debe centrarse en los siguientes indicadores:

Las fronteras o límites: Se refiere a la separación o cercanía virtual, emocional y conductual entre los subsistemas que permite o prohíbe las interacciones entre uno y otro, plantea Suares (2002). Además, la frontera, agrega Umbarger (1999, p. 25), "se puede experimentar como las interacciones gobernadas por reglas, que de manera regular se producen entre las personas durante períodos largos". Según este mismo autor, los problemas se presentan cuando esos límites o fronteras son rígidos o difusos. Son rígidos cuando no se permite el ingreso de un subsistema a otro, provocando distanciamiento y desprendimiento entre los subsistemas. La demarcación demasiado rígida, conlleva al desapego y al aislamiento en la medida que se ignora el compromiso recíproco relacional. Cuando la independencia entre los subsistemas es grande, los movimientos o el estrés se atienden en forma menos inmediata que si los mismos fueran muy dependientes o estuvieran muy ligados.

Los límites o fronteras son difusas cuando no permiten la indiferenciación entre 
los subsistemas, favoreciendo las relaciones aglutinadas. La demarcación demasiado débil de los límites conlleva a un apego excesivo y aglutinado entre los miembros, prevaleciendo entonces la unidad de pensamientos y sentimientos por sobre la intimidad e individuación física, emocional y mental.

La jerarquía o separación clara entre las generaciones: Cada subsistema tiene un rol específico y una posición al interior del sistema. Resulta claro que madre y padre (o bien las personas adultas) tienen responsabilidades diferentes en relación con el subsistema filial (o personas menores), en cuanto a la autoridad y la responsabilidad. El subsistema parental conforma la columna vertebral de la familia, y debe brindar seguridad y protección al sistema familiar en general, y al filial en particular. El problema se presenta cuando se construyen coaliciones intergeneracionales y se confunde el rol jerárquico. Cuando no hay claridad jerárquica se presentan las coaliciones, que son los agrupamientos intergeneracionales en contra de una de las figuras progenitoras.

Triangulación: en la organización de la familia subsisten los triángulos cambiantes y coaliciones fluctuantes sin generar celos ni inseguridad entre los miembros. Ello permite que quienes conforman el sistema se enriquezcan por la libertad de experimentar todas las combinaciones y permutaciones posibles de relaciones triangulares. La libertad de unirse libremente de acuerdo a intereses comunes, es una elección y no responde en ningún momento a una imposición. Cuando la triangulación se vuelve rígida impidiendo así la rotación esperada, el sistema familiar entra en crisis.

La pertenencia y la separación: La estructura de la familia brinda a cada integrante la experiencia de formar parte de un todo, seguro y protector, al mismo tiempo que estimula la independencia y la manifestación del sí mismo o la individualidad. Cada quien cuenta con la libertad de salir e ingresar al sistema familiar cuando lo considere necesario, nunca se deja de pertenecer.
Ciclo vital: La familia en la medida que evoluciona debe ir cambiando, pasa por diferentes etapas: del ser pareja a tener bebés, infantes, adolescentes hasta la convivencia con la descendencia adulta y adulta mayor. En cada uno de esos estadios la familia debe cumplir con tareas específicas y debe pasar necesariamente por esos cambios o crisis de desarrollo. Para distintas familias unas transiciones son más dificultosas que otras, y ponen a prueba la capacidad de reorganización del sistema familiar, la capacidad de apertura, y la forma de enfrentar los conflictos intra y extra sistema.

La atención del conflicto: El conflicto según como se maneje, puede ser visto y utilizado como el fertilizante de la vida, que aunque no es agradable, es decisivo para lograr el crecimiento óptimo. El manejo que se haga de las crisis y del conflicto puede permitir cambios significativos para el sistema familiar. Con una visión limitada y cerrada al cambio y con un manejo inadecuado de las dificultades conflictivas, el sistema familiar se puede atascar y se convierte en un ambiente inadecuado para el crecimiento y desarrollo de la familia en general y de las personas que la conforman en particular.

La distribución del poder: el manejo del poder en forma adecuada hace que el sistema no se mueva en el caos. Las personas adultas deben llevar el liderazgo en forma consensuada por la responsabilidad de cuido, protección y formación que debe cumplir con la prole.

En el ejercicio del poder y para influir en el desarrollo de la prole, el subsistema parental, según Musitu, Román y Gutiérrez (1996), debe hacerse uso del afecto (estimular la cooperación, ofrecer ayuda, reconociendo y elogiando las capacidades) y del control (capacidad de disciplinar) al mismo tiempo. El uso del poder legítimo implica respeto y autoridad de las figuras progenitoras en el acto de disciplinar (influir en la prole). El subsistema parental haciendo uso del poder, no abuso de éste, guía con respeto y ofrece libertad al subsistema filial, para que éste desarrolle sus propias 
capacidades en un marco de seguridad. El buen uso del poder por parte del subsistema parental brinda, según Austin (1992), seguridad, creatividad y control, además de herramientas para ejercitar el permanente desarrollo de la inteligencia de la prole.

La comunicación: Ésta, según Satir (2002, p. 65) "abarca la diversidad de formas como la gente transmite información: ¿qué da y qué recibe, cómo la utiliza y cómo le da significado". Según esta misma autora (2002), es posible re-aprender patrones adecuados de comunicación al interior de las familias. El reto es que las personas puedan expresar lo que piensan, sienten y desean, pues las relaciones humanas se enmarcan en el intercambio constante de pensamientos, sentimientos y reacciones corporales, y según esta misma autora, las buenas relaciones dependen, en gran parte, de que las personas sepan interpretar las interacciones del uno para con el otro.

La búsqueda de la homeostasis y del cambio: Tal y como se mencionó anteriormente, lo esperado es que el sistema familiar se mueva en un constante equilibrio-desequilibrio, en un proceso de permanente movimiento ya que la falta del mismo llevaría al sistema a un estado de caos.

\section{Principios metodológicos orientadores de la intervención}

En este apartado se presenta en forma resumida los principios teóricos y metodológicos que sustentan la intervención realizada.

\section{Intervención con perspectiva estructural sistémica}

Las familias buscan ayuda cuando entran en crisis, generalmente personifican el problema en un subsistema, que con frecuencia es la persona que según la familia presenta dificultades. No obstante, la acción actúa sobre la estructura, o sea en "el conjunto invisible de demandas funcionales que organizan los modos en que interactúan los miembros de esa familia" (Minuchin, 1985, p. 86). Para lograr los cambios estructurales se requiere de la modificación de la familia como un todo, se enfatiza en las maneras de organización y del funcionamiento del sistema familiar.

La intervención estructural no sólo permite a las familias la exploración de sus áreas fuertes, sino que también las estimula a trazar fronteras claras entre las generaciones, a distribuir jerárquicamente las competencias y a acomodar esa estructura interna a los propios ciclos evolutivos y a las demandas del entorno. Para tal efecto, se pone especial atención en el proceso interactivo que muestra el sistema familiar, en otras palabras, "la secuencia discreta y limitada en el tiempo, de conductas que constituyen una transacción" (Umbarger, 1999, p. 31). Las pautas de interacción, en el sistema familiar, según Minuchin (1985), se van construyendo en forma evolutiva y conjugan necesariamente las reglas de participación (¿quién participa y cómo participa?), el nivel cognitivo y perceptivo (¿cómo debe entenderse la conducta o una clase de conducta), además de la comunicación entre los subsistemas.

Otro principio de intervención importante en esta perspectiva se refiere a que el aprendizaje se adquiere en la acción, por eso es que, en las sesiones estructurales se practica el rompimiento de patrones inadecuados de interacción y la búsqueda de nuevas conductas que los reemplacen. Lo anterior se logra, primero, identificando la secuencia de conductas que forman la interacción para luego ensayar con la familia nuevas secuencias que sustituyan a las anteriores enfatizan Minuchin y Fishman (1985). El cambio se logra en la sesión y si se captó, en ese mismo momento, el sistema familiar lo introduce y lo mantiene en su dinámica cotidiana. 


\section{Rol profesional}

Quien facilita, se desempeña como un ente transformador, y facilitador de cambios, debe actuar sobre el drama familiar e introducir desequilibrio en busca de modificar el sistema y desarrollar un nivel diferente de homeóstasis en el mismo.

Para lograr los cambios, el proceso terapéutico demanda, en quien facilita, el establecimiento de una relación que va desde la cercanía hasta la distancia con el sistema familiar, con el cual conforma el sistema terapéutico. La posición cercana permite la confirmación y la expresión de afecto y la actitud empática, mientras que en la intermedia se asume el papel de observador o espectador (papel oyente activo, neutral, hace preguntas de secuencia y circulares, rastrea información), y en la posición distante se espera un rol más directivo que permite la asignación de tareas a la familia en busca de la reestructuración del sistema familiar.

\section{Estrategias de intervención}

A continuación mencionaré las tres estrategias que Minuchin y Fishman (1985), sugieren para el logro de la reestructuración del sistema familiar:

Cuestionamiento del síntoma: Se reencuadra el hecho de que el problema no reside en el paciente individualizado, sino en algunas de las pautas de interacción del sistema familiar. Para ello se induce a la familia a la búsqueda de nuevos comportamientos afectivos, cognitivos y de conducta para atender las demandas y necesidades de todos.

Cuestionamiento de la estructura familiar: Se identifica y se interviene en las coaliciones, alianzas, conflictos explícitos e implícitos, así como las formas en que los miembros de la familia se agrupan en la resolución de conflictos ya que tiene que ver con la manera en que se relacionan subsistemas en el sistema familiar.
Cuestionamiento de la realidad familiar: se parte de que las pautas de interacción familiar obedecen a la realidad tal como es vivenciada por quienes integran la familia. Para modificar la visión de la realidad por la que se rigen los miembros de la familia se requiere un cambio en la estructura. Asimismo, el cambio en la estructura va a influir en un cambio en la visión del mundo o de la realidad de la familia.

\section{Proceso de intervención}

La familia que llamaremos Sánchez Madrigal, fue referida a la terapia de familia por la pediatra del niño. Ella en la valoración que realizó del menor identificó la dificultad de las figuras progenitoras para disciplinar a los tres hijos. Además desconfirmó el diagnóstico de déficit atencional que sugería la maestra. Se me asignó la familia y trabajé con ella en mi propio proceso de formación como terapeuta familiar bajo la supervisión del profesor Gerardo Casas.

Realicé ocho sesiones con una duración aproximada de hora y semana en un período de cuatro meses. Para efectos de este artículo resumo el proceso vivido por el sistema familiar, destacando los cambios estructurales que cronológicamente se fueron realizando.

\section{Evaluación inicial del sistema familiar}

La valoración inicial del sistema familiar la realicé en la primera sesión cuyo propósito, para quien recibe a la familia, es leer la danza de la familia en función de una queja específica que generalmente se acompaña del pedido de la familia. Además, la evaluación permite el planteamiento de las metas e hipótesis de trabajo con el sistema familiar. En cada una de las siguientes sesiones retomé los cambios del sistema familiar respecto a la 
sesión inicial, para tener siempre presentes las necesidades de la familia e ir ajustando las metas de intervención.

Esta es una familia de bajos recursos económicos que vive en una situación muy precaria. Residen en Rincón Grande de Pavas, donde alquilan un cuarto en la casa de la familia de origen de Karen. Ella y Antonio, como pareja muestran deseos de salir de esa situación y de proteger a los tres hijos del ambiente de drogadicción y de violencia que les rodea. En este sentido, el hecho que los niños estén escolarizados representa para la pareja una esperanza.

El sistema familiar está conformado por los siguientes subsistemas:

Conyugal: Padre, Antonio de 37 años, con primaria completa. Se desempeña como misceláneo en una fábrica en Pavas y Karen de 23 años, con primaria incompleta. Ella atiende los oficios domésticos de su familia y además ayuda a su madre en los quehaceres de la casa. Como pareja están enfrentando alejamiento emocional por la dificultad de privacidad en que viven y por el rechazo a Antonio de parte de la familia de Karen.

Subsistema parental: además de las limitaciones económicas para llenar las necesidades básicas, se les estaba dificultando compartir el liderazgo para disciplinar a sus hijos. Además, hay confusión en la línea de autoridad, los niños reciben órdenes y agresión de parte de los abuelos, los padres, y de los tíos maternos.

El subsistema filial: conformado por Mauricio de ocho años cursa el primer grado, Jorge de seis años y está en Kindergarten y Mario de cuatro años quien permanece con su madre. Según la pareja los niños pelean entre ellos, se agraden y además no les obedecen. Sin embargo, presentan a Jorge como el problemático debido a las dificultades en el rendimiento escolar y al mal comportamiento en el kinder.

Subsistema extendido: está integrado por Israel de 70 años padrastro de Karen, quien desde 1993 convive en unión libre con Zaira, madre de Karen. Esta pare- ja tiene un hijo de ambos, Sergio de 8 años de edad. También viven aquí los dos hermanos de madre de Karen; ellos son: Ronald de 33 años y Jairo de 22 años. Tanto Ronald como Jairo tienen problemas de drogadicción, muestran conductas violentas entre ellos y con el resto de la familia.

El sistema familiar presenta un estilo transaccional aglutinado, con límites muy débiles entre los miembros y maltrato permanente. Se observan coaliciones entre el padre y el hijo mayor y por otro lado, la madre con el hijo menor. En esta situación, Jorge pareciera estar fuera, tratando de desequilibrar esas coaliciones con su comportamiento. Estas coaliciones definen la forma en que se organizan para dormir. El padre y el hijo mayor duermen en una cama individual y la madre duerme con el menor y con Jorge en una cama doble.

El liderazgo se ejerce con poca claridad, situación que favorece la manutención de las dificultades de este sistema familiar, cuales son: la disciplina poco eficaz, la dificultad para desarrollar hábitos, la confusión en la línea jerárquica y la necesidad de aprender a negociar para enfrentar el conflicto.

El estilo de comunicación es bastante agresivo, centrado en amenazas, gritos y se utiliza el castigo físico para que los hijos acaten las órdenes. Ante esta situación la reestructuración en este sistema familiar debe ser dirigida a:

el ordenamiento de la jerarquía entre los subsistemas; el delineamiento de límites o fronteras entre los subsistemas; la definición de roles y funciones entre los subsistemas y

a favorecer la comunicación directa entre los subsistemas.

\section{El pedido de la familia}

La familia presenta a Jorge como el problema porque la maestra quiere suspenderlo del kinder por presentar conductas 
agresivas, además de dificultades para permanecer sentado y poniendo atención en el aula. Sin embargo, al explorar más sobre el pedido, éste se amplía.

T.: ¿En qué les puede ayudar esta terapia de familia?

Karen: A cambiar a Antonio, él agrede a los niños y a mí con palabras. A sacarnos adelante como papás también.

Antonio: A cambiar la forma de tratarnos y entre nosotros como papás.

\section{La clarificación de las fronteras entre los subsistemas}

Para atender la diferenciación entre los subsistemas, se inició con el subsistema conyugal

T.: ¿Qué les mantiene juntos?

Antonio: Los güilas.

Karen: No es solo los güilas.

T.: Me gustaría que se pusieran de frente, se tomen de las manos y conversaran sobre eso.

(El niño menor corrió y se sentó en el regazo del padre. El lo acogió, yo le dije al padre si era posible que lo sentara en la silla en que el niño estaba; él le dio la orden al niño, pero éste no la acató). ustedes?

T.: ¿Qué está haciendo el niño, según

Karen: Está protegiendo al papá.

T.: De qué o de quién lo protege?

Karen: Ellos quieren mucho al papá, y ven que en mi casa no lo quieren.

T.: Pueden captar la gran tensión que existe en este niño.

SILENCIO

T.: Continuemos.

Karen: Antonio, yo estoy con usted porque lo amo, además usted es muy importante para mis hijos, ellos lo adoran a usted.

Antonio: ¿Entonces por qué no quiere que nos cambiemos de casa?

Karen: Es que usted quiere que nos vayamos y que las cosas de mi familia son de ellos y que yo no me meta con ellos.

Antonio: Nosotros somos aparte, las cosas de ellos son de ellos, nosotros tenemos que estar con los hijos y no meternos en pleitos.

Karen: Es que yo quiero que sea una casa cerca para no cambiar a los güilas de la escuela, que les quede cerca. Yo quiero estar con los güilas para que no los maltraten, mi padrastro los maltrató estando yo ahí, ahora si no estoy? Llevamos dos meses de no pagar.

Antonio: Juntemos la plata y nos vamos. Yo no puedo hablar con su papá por mi enfermedad (problema pulmonar), entonces él le reclama a usted, usted a mí y entre los dos agredimos a los niños.

Karen: Bueno está bien, vámonos y yo no me meto en los problemas de ellos.

Les reforcé la capacidad de tomar decisiones como una fortaleza entre ellos. La pareja llegó a un acuerdo sin muchas dificultades, además se acercaron emocionalmente y definieron una meta en común (luego se les asignó la tarea de realizar actividades como grupo familiar). Al fortalecerse la alianza conyugal, el padre y la madre logran un avance en compartir el liderazgo. Antonio se ubica ahora en el subsistema conyugal y no en el fraternal. La madre logra un avance en el desvinculamiento con el subsistema ampliado, se acerca más a sus hijos, y define límites para el trato de sus hermanos con sus hijos. En la siguiente sesión:

T.: ¿Cómo han estado?

Padre: Hemos pasado muy bien, estamos más unidos.

Madre: Hemos estado bien entre nosotros, conversamos más, yo estoy contenta con él (esposo).

T.: ¿Qué cosas han hecho diferente?

Madre: Ahora pasamos más tiempo juntos, en las tardes yo me encierro con los güilas en el cuarto. La idea es mantenernos un poco más aparte de mi familia.

T.: ¿De quién fue la idea de hacer ese cambio?

Padre: Yo tuve la idea y conversé con Karen y los dos estuvimos de acuerdo.

T.: Qué bueno que conversaran y hayan tomado esta decisión en conjunto. 
¿Qué efectos ha tenido esta decisión en ustedes como familia?

Madre: Muy bueno porque yo los pongo a hacer tarea, después juegan ahí, de lo más bien juegan entre ellos, pelean menos entre ellos y evitamos problemas con mi familia.

Antonio: Cuando yo llego a la casa compartimos más entre nosotros.

T.: Karen ¿Cómo se siente usted?

Madre: Muy bien, yo estoy más con ellos y en la noche se une Antonio y está la familia junta.

Karen al sentirse apoyada por su esposo al mismo tiempo que se concentró en su familia de procreación, inició la clarificación de fronteras con su familia de origen (subsistema extendido).

T.: ¿Qué otra cosa han hecho estos días para sentirse mejor entre ustedes?

Madre: Yo me les paré en raya a mis hermanos en la casa. Ellos maltratan a mis hijos; yo les dije: Si tienen algo que decirles a mis hijos, me lo dicen a mí, yo soy su mamá y a mí me toca corregirlos. Les pueden hablar por bien pero no los van a maltratar. Aquí estoy yo.

T.: ¿Cómo se sintió usted al hacer eso?

Madre: Muy bien, además mi mamá me dijo que estaba bien hecho, que era hora de que yo hiciera eso. Ya ve, casi no los han vuelto a maltratar. pecto?

T.: Antonio, ¿qué opina usted al res-

A.: Me parece muy bien, los dos hablamos de eso y estamos de acuerdo.

T.: Me parece que el hecho de que ustedes estén más unidos tomando acuerdos en conjunto les coloca en una posición más fuerte para defender tiempo y espacio para ustedes cinco como familia.

Madre: Estamos más unidos, y más contentos.

Padre: Sí, estamos más contentos.

K.: El problema que tenemos ahora es con Mauricio. Está saliendo mal en la escuela, no le hace caso a la maestra. Jorge está mejor portado y mucho más tranquilo. La maestra me manda recados de Mauricio, que él camina por toda la clase, desconcentra a los demás. En los exámenes que ha hecho ha salido muy mal.

Con este comentario de la madre, se nota un nuevo acomodo-desacomodo en la familia. Como el padre rompe la coalición con Mauricio éste debe ubicarse en el subsistema fratrenal, situación que no comprende aún y le provoca desconcierto que lo muestra en su comportamiento de desobediencia tanto en la casa como en la escuela, y Jorge que estaba fuera de las coaliciones, al tener más espacio y acceso a las figuras progenitoras mejora su comportamiento.

T.: ¿Cómo se está portando Mauricio en la casa?

Madre: Conmigo bien, lo pongo a hacer las tareas y las hace, si están malas las vuelve a hacer.

T.: ¿Y en otros momentos?

Madre: A él le gusta oír lo que uno habla. La maestra me manda a llamar, yo le digo, no venga y él llega.

T.: Entonces el niño no siempre hace caso. En el ejemplo que usted puso anteriormente, evidentemente Mauricio no hizo caso, ¿tuvo después alguna consecuencia?

Madre: No, yo le digo vaya a la casa y él no se va.

T.: En esa situación ¿quién mandó?

Madre: Él.

T.:¿Cómo ven ustedes eso?

Madre: Mal.

Padre: Eso no está bien.

T.: ¿Cómo podrían ustedes dos manejar diferente esta situación?

Madre: Aquí hay un problema, le voy a decir la verdad, el papá lo alcahuetea mucho, con él hace lo que le da la gana, esos dos son muy pegados. Desde que nació parece que tiene sólo un hijo, yo le digo que tiene tres hijos, que los tiene que atender igual.

Padre: A mí sí me hace caso.

Madre: El problema es que cuando yo no lo dejo ir a jugar afuera usted sí se lo permite, entonces él se envalentona y piensa 
que a mí no me tiene que hacer caso. Yo siento que él me desautoriza a mí.

T.: ¿Cómo afecta eso a Mauricio? SILENCIO

T.: Me hubiera gustado que Mauricio hubiera estado acá (lo dejaron acompañando a la abuela materna); como no está, yo quiero que tomen esta silla, y cada uno la jale para su lado, si esta silla fuera Mauricio ¿Cómo se sentiría él?

Padre: Ay, no, eso está mal, se siente jalado, como mareado. debe hacer

Madre: Seguro no sabe qué es lo que

T.: ¿Qué podrían hacer ustedes diferente para que Mauricio sepa con claridad lo que él debe hacer?

Padre: Si ella da una orden, yo la debo apoyar.

Madre: Sí, así él no me desautoriza a mí, y yo tampoco a él. Cuando yo no lo dejo salir y usted sí lo deja, ahí me está desautorizando.

Con la escenificación la pareja revela una secuencia de comportamiento que debe ser cambiada: la desautorización entre madre y padre permite que se diluya la autoridad parental y la capacidad para disciplinar.

\section{Clarificación de la jerarquía y los roles entre los subsistemas}

T.: ¿Qué cosas diferentes pueden hacer el día domingo?

Madre: Hay una cosa, yo quiero que el domingo Antonio me ayude con los güilas, que haga tarea con ellos, o que los lleve a jugar. Yo paso toda la semana con ellos, los hicimos entre los dos, los tenemos que cuidar entre los dos.

Padre: Bueno, yo el domingo me puedo encargar de ellos. Pero yo le digo a ella que no tiene que trabajar tanto en la casa.

En este momento a Mario, el hijo menor se le cayeron unas monedas.
Antonio: Mario déme esas monedas.

Madre: Antonio, no, porque se va a poner a llorar.

T.: Hagamos un alto acá y hablemos sobre lo que acaba de pasar aquí.

Madre: Ay, perdón, acabo de desautorizar a Antonio.

Padre: Cierto, qué fácil que nos sale. Ella decía que no lo hacía, pero ya veo que somos los dos.

T.: Lo importante es que los dos están de acuerdo en apoyarse y así pueden ir cambiando juntos. Me parece necesario que durante los próximos días observen los momentos en que ambos se desautorizan.

En la siguiente sesión, se le dio seguimiento al patrón de desautorización.

T.: ¿Cómo les fue en la semana?

Madre: Nos fue bien, nos apoyamos y no nos desautorizamos.

Padre: Ya aprendimos que si nos apoyamos nos va mejor con ellos.

T.: Recuerdan ahorita algún momento o situación específica en que actuaron juntos?

Madre: Sí, Mauricio quería salir, yo le dije que no y Antonio me apoyó, también dijo que no.

Hasta este momento los niños no habían cesado de gritar y de subirse encima de las sillas. Tanto la madre como el padre les pedían que hicieran silencio, que se sentaran, y los niños no atendían al pedido de los padres. Se observa acá otro patrón importante, en esta familia No, no significa no.

T.: ¿Se sienten incómodos por el comportamiento de los niños?

Padre y madre respondieron afirmativamente.

T.: ¿Cómo les gustaría que se comportaran los niños ahora?

Madre: Yo quiero que estén sentados con nosotros aquí.

T.: Antonio, ¿qué quiere que hagan los niños ahora? 
Padre: Lo mismo que Karen, que estén sentados aquí con nosotros.

T.: Si eso es lo que quieren llamen a los niños y les dan esa orden.

Madre: Nosotros queremos que ustedes se sienten queditos y estén con nosotros.

Los niños en coro: No, no queremos y empezaron a alegar, luego se salieron del salón.

T.: ¿Qué tan efectiva fue la orden que dieron?

Madre: No nos hicieron caso, así es en la casa, ésa es la lucha eterna.

Padre: Sí, ellos no nos hacen caso.

T.: Llamen a los niños y entre los dos le dan la misma orden y manténganlos sentados por unos cinco minutos en las sillas.

Madre y padre salieron del salón en busca de los niños. Por sugerencia mía ubicaron las dos sillas de ellos en frente de las tres sillas de los niños. Les dieron la orden y los niños empezaron a resistirse y padre y madre les rogaban y les amenazaban, se paraba uno, luego el otro, y no cumplían con la orden.

T.: Hagan algo diferente para que los niños hagan caso.

Seguían rogando, ahora se acercaban a los niños y los llevaban al asiento, éstos se levantaban apenas se les sentaba. Seguían desafiando la autoridad de los padres. El padre mostró enojo y les dijo con un tono firme: se sientan ya porque yo lo digo. (Los niños se sentaron pero se volvieron a levantar de las sillas).

Madre: Siéntense ya porque si no les vamos a castigar. (A ella se le puso roja la cara).

Los niños se sentaron, Mauricio y Mario callados y Jorge llorando.

T.: ¿Qué fue lo que hicieron diferente para que los niños hicieran caso?

Madre: Les dejamos de rogar.

Padre: Además mi voz fue más fuerte, y no les pegamos.

Madre (a Jorge): Vea que si no se queda allí no lo llevo a ver las palomas...
T.: ¿A qué se debe esa amenaza al niño, si ya había hecho caso.

Madre: Es que lo que yo quería que él estuviera del aquel lado, donde yo puse la silla él no ha hecho caso todavía.

T.: ¿Entonces usted no está conforme todavía?

Madre: Jorge no hace caso.

T.: Haga algo para que él le haga caso.

Madre: Jorge ponga la silla ahí, en esa mancha negra del piso.

Jorge: No, aquí es donde yo la quiero.

Esta escena duró varios minutos. Jorge continuaba retando y desafiando la autoridad de la madre.

T.: Papá, ¿cómo puede usted apoyar a Mamá para que Jorge cumpla con lo que se le pide?

Antonio: Lo levanta del suelo y lo lleva a la silla y le dice "no se levanta más de aquí".

Jorge suelta el llanto y todo "moquiento", se levanta de nuevo y dice: "Yo no quiero esa silla", y se fue a sentar a otro lugar.

Se presenta otra serie de puntuaciones entre madre hijo y padre, sin lograr que el niño hiciera lo que ambos querían. El padre busca cambiar la orden que había dado la madre.

Madre: (a Jorge): Ahí no es.

Jorge: Aquí es donde yo quiero, y se quedó sentado por segundos y luego se volvió a levantar de la silla y se sentó en el suelo.

Padre: Bueno Jorge, siéntese en esa otra silla.

T.: Mantengan la orden inicial. Todavía no logran que el niño se siente dónde ustedes quieren (el padre desautorizó a la madre).

Madre: Yo me pongo a rogarle ahorita que se quite de ahí, él no lo hace.

T.: No le ruegue, acabamos de darnos cuenta que no sirve rogar, haga usted algo diferente 
Padre: Sin rogar.

T.: Haga algo diferente, algo que se le ocurra en este momento para que el niño le haga caso.

Madre: (a Mario) Córrase para acá, Mauricio para acá y usted se queda allí (reacomodó a los niños que sí hicieron caso con anterioridad). Jorge también se cambió de silla, pero no permaneció donde la madre quería.

T.: Parece que deben hacer algo diferente. ¿Qué otra cosa podrían hacer para que Jorge cumpla con la orden?

Madre: Así pasa en la casa, hasta que no le peguemos no vamos a terminar con esto.

T.: ¿Es eso lo que quieren hacer?

Padre: No.

T.: ¿Qué otra cosa podrían hacer entonces? ¿Antonio, cómo puede usted ayudar a mamá para que Jorge cumpla la orden que se le pide?

El padre se levanta de su silla y agarra a Jorge y lo sienta de nuevo.

En este momento, Mauricio, el hermano mayor quiso levantarse de su silla y pedirle a Jorge que se sentara. El padre le dijo:

Mauricio siéntese, no se meta, es entre su mamá y yo.

(Esta transacción confirma que la coalición padre-hijo mayor se debilitó, mientras que la alianza del sistema conyugal está fortalecida).

Padre: Él tiene que hacer caso. Jorge, siéntese en esa silla. (Jorge se levantó y salió corriendo).

T.: Mamá y papá vayan entre los dos, traen a Jorge y entre los dos lo sientan en la silla y se queda uno a cada lado para que no se levante. Lo hicieron, el niño lloró desconsolado, y se abrazó a la madre, quien estaba en la silla de a la par. El padre también lo abrazó.

T.: ¿A mamá y papá les parece que los niños pueden dibujar ahora? (Recordemos que fue un pedido que los niños hicieron al llegar)
Ambos: Sí.

T.: ¿Qué fue lo que hicieron diferente para controlar a los niños?

Padre: No les rogamos, y entre los dos nos apoyamos.

Madre: Yo en la casa nunca les doy las órdenes claras ni qué es lo que quiero que hagan.

T.: ¿Cómo se sienten?

Madre: Me siento bien.

T.: Y usted ¿cómo se siente?

Padre: Bien, juntos lo hicimos.

T.: Yo estoy muy de acuerdo con ustedes; juntos es como han logrado controlar a los niños. Veo que tienen mucha paciencia y fortalezas para educar a sus hijos. Otra cosa es que, para ambos es muy importante la educación de los hijos y tienen disposición para hacerlo.

El padre y la madre confirmaron su autoridad ante los hijos en la medida que se identificó el patrón de desobediencia; para el niño "no" significa tal vez, que si presiona con el llanto lo transforma en sí. Quedó muy claro para los padres que el niño utiliza el llanto como una estrategia; por lo tanto el dejarlo llorar puede ser la forma de desarmar al niño y hacerle obedecer. Además, el subsistema conyugal está unido para actuar, y eso el niño lo sabe.

En la siguiente sesión:

Jorge, que estaba sentado en su silla, se levantó y le dijo a la madre que necesitaba ir al baño. La madre primero le dijo que "no", el niño lloró, el padre volvió a ver a la madre y ella lo dejó salir. En ese momento, la madre afirmó: a él (el padre), no le gusta que ellos aguanten...

T.: ¿Qué sucedió acá?

Madre: Yo le dije que no, pero siempre fue.

T.: ¿Qué la movió para dejarlo salir después de decirle como cuatro veces que no?

Madre: Me cuesta verlo llorar y no es bueno que aguanten. 
T.: ¿Su esposo le dijo con los ojos que lo dejara salir?

Madre: Sí, a él no le gusta que aguanten...

T.: ¿Ni que llore? Esa es una forma de descalificar, aunque no fue con palabras, el efecto es el mismo.

Padre: Es cierto (sonríe).

T.: ¿Con el llanto el niño logra lo que quiere?

Madre: Sí, él me manipula con eso.

T.: ¿Cuándo eso sucede quién tiene la autoridad?

Padre: Jorge, hizo lo que él quería.

T.: (a Jorge) ¿Qué debió haber hecho mamá y papá para que no salieras?

Jorge: No dejarme salir.

Mario: Si no le dejan él no va afuera.

T.: ¿Se dieron cuenta de la claridad que tienen los hijos del manejo que ustedes hacen con ellos?

Padre: Es un jueguito que tenemos.

En ese momento, Mario quiso salir para ir al baño y Jorge se paró y quiso salir de nuevo con el motivo que necesitaba orinar. La madre cerró la puerta y no les dejó salir. Jorge se enojó mucho, se tiró al suelo, se puso a llorar y hasta pateó la puerta. En el llanto decía yo quiero ir, la madre le respondió "no es no" y allí se mantuvo en ese pulso por unos minutos.

Madre: Eso pasa en la escuela, le dicen que no y hace lo que él quiere.

T.: ¿Pasa eso en la casa también?

Madre: Pero ya no más, "no es no". Que llore lo que quiera, pero no sale. El problema en la casa es que mis hermanos no aguantan oír llorar y me regañan a mí.

Padre: El llanto es un arma que Jorge tiene, ya me doy cuenta de eso.

\section{La familia habla sobre los cambios logrados}

Para la octava sesión la familia logró la meta de independizarse de la familia de origen de Karen, situación que favoreció el ambiente familiar.

T.: Recuerdan ustedes que la terapia la iniciamos debido a la petición que hicieron por el comportamiento de Jorge que mostraba conductas agresivas, de hiperactividad e impulsividad. ¿Cómo ven ustedes esa situación actualmente?

Madre: Jorge, Ahora como ya yo lo manejo a la manera mía, él cumple órdenes, pide permiso, ayuda en el oficio, acepta la autoridad de la maestra y la de nosotros, ya él cambió.

Padre: Jorge además de eso, ha mejorado en el lenguaje, es un niño colaborador.

Madre: La maestra dice que Jorge ahora participa en la clase, él era muy apartado. Ahora participa, hasta canta, juega con plasticina y participa en el círculo. En la casa busca papeles para pintar, y de él nace decir "voy a ayudarle a mamá". Ya no tengo que pegarle, se le castiga con no dejarlo jugar por un rato.

T.: Qué increíble el cambio que ha tenido esta familia ¿Qué cosas consideran ustedes que deben continuar haciendo para no volver a la situación inicial?

Madre: No volver a la agresión, que nosotros sigamos como los estamos educando. Si perdemos el control ellos se desubican y entonces vuelven a la malacrianza. Otra cosa es poder mantenernos en la casa apartados de mi familia. También dialogar más en la casa para el crecimiento de ellos.

T.: ¿Qué otras cosas deben hacer para mantener el cambio en ustedes?

Padre: Mantenernos en casa aparte de la familia de Karen, eso es lo más importante; el manejo de los güilas entre los dos, nosotros juntos les podemos a ellos. Tenemos que dialogar en la casa, compartir con ellos, salir a pasear, apoyarnos en las órdenes que damos, no descalificarnos, apoyarnos entre nosotros. Ahora yo siento que sí tengo una esposa, antes no.

T.: ¿Qué otra cosa podrían hacer? 
Madre: Como yo tengo trauma de no tener papá yo quiero que Antonio sea más papá.

T.: Colóquense de frente y dialogan entre ustedes sobre eso, ¿qué significa ser más papá?

De frente Karen prosigue: Que usted cuando llegue los busque, habla con ellos sobre la escuela, lo que han hecho. Además que revise los cuadernos y me ayude con lo de la escuela.

Padre: Sí, yo puedo tener más comunicación con los hijos. Lo de la escuela si usted no me dice yo no sé, pero si usted me dice yo participo. De ahora en adelante les voy a revisar cuadernos y ayudar a hacer las tareas.

Madre: Yo le voy a seguir comunicando.

T.: Otra de las cosas que ustedes pedían fueron: mejorar la relación entre ustedes, y ser mejores padres. ¿Qué piensan de eso ahora?

Padre: Ya eso está cumplido.

Madre: Ya hemos logrado lo que queríamos. Sería bueno que nos reuniéramos una vez después de que pasen las vacaciones para ver si yo puedo manejar sola a los güilas cuando no están en la escuela. Me da un poco de susto, antes Mami me ayudaba.

T.: ¿Qué piensa Antonio de eso?

Padre: Me parece bien que suspendamos un mes y después venimos a ver cómo nos va.

Es la misma familia la que define la finalización del proceso terapéutico, según la pareja se cumplió con el pedido que plantearon al inicio.

\section{Consideraciones finales}

Durante el proceso esta familia logró cambios muy significativos y en un período corto de tiempo. El deseo de estar mejor, y sobre todo, el de educar bien a sus hijos (bajo el lema: "el palito para que crezca rectito hay que enderezarlo desde chiquito"), y a pesar de las dificultades económicas, movió a este sistema familiar a lograr las siguientes reestructuraciones:

1. Con respecto al subsistema conyugal: acercamiento emocional, mejoramiento de la comunicación, lograron separarse físicamente de la familia de origen de ella, y restablecer otras formas de relación con esa familia.

2. En cuanto al subsistema parental: fortalecieron la función parental en cuanto lograron acuerdos sobre la forma de disciplinar a los niños. Aprendieron a no descalificarse, a poner orden juntos, a cumplir la norma "no es no" y a buscar diálogo con los hijos.

3. El subsistema filial: ninguno de los hijos forma parte ahora de coaliciones estables; están más unidos, comparten más entre ellos, también han mejorado el comportamiento en la escuela.

Esta familia desde el inicio del proceso intuía las situaciones que se les estaban dificultando, y con poca guía Karen y Antonio fueron encontrando las salidas y tuvieron la perseverancia para reencontrarse y asumir la formación de los hijos.

No todas las familias de los centros educativos requieren del tipo de intervención que recibió esta familia. Sin embargo, no se puede desconocer la necesidad que tienen las familias de mejorar la comunicación, la dificultad de las figuras progenitoras respecto a la educación de la prole, el manejo adecuado del poder inter e intrageneracional al interior de las familias, la responsabilidad de las familias en la transmisión de valores de vida, la violencia de género, entre otros. Estas necesidades de las familias costarricenses aparecen en los informes del Proyecto del Estado de la Nación. Ante esta realidad vale la pena preguntarse: ¿qué aporte puede ofrecer el sistema educativo en general y los 
departamentos de Orientación en particular para mejorar la calidad de vida de las familias? Vale la pena asumir el reto con una posición proactiva. Considero necesario que las universidades como formadoras de profesionales en Orientación, refuercen el currículo con teoría y metodología para educar, orientar y asesorar a familias. Por otro lado, es urgente que el Ministerio de Educación pública, por su misión como ente rector del sistema educativo (le corresponde la formación de la infancia y la adolescencia escolarizada del país), defina e implemente políticas y acciones a nivel nacional, que favorezcan la asesoría a las familias desde los centros educativos.

\section{Referencias bibliograficas}

Austin, G. (1992). Amor y poder entre padres e hijos. México: PROMEXA.

Barylko, J. (2005). Familia el arte de la convivencia. Argentina: Editorial Suramericana. S.A.

Hernández, A. (1998). Familia, ciclo vital y psicoterapia sistémica breve. Colombia: Editorial El Búho.

Jaramillo, J. (2002). Familia y colegio. Colombia: Grupo editorial Norma.

Minuchin, S. (1985). Familias y Terapia familiar. México: Gedisa.

Minuchin, S. y Fishman, H. (1985). Técnicas de terapia familiar. España: Paidós.
Minuchin, S., Lee, W. y Simon, G. (1998). El arte de la terapia familiar. Barcelona: Paidós.

Musitu, G., Román J. y Gutiérrez, M. (1996). Educación familiar y socialización de los hijos. Barcelona: Idea Books, S.A.

Nugent, F. (1990). An Introduction to the Profession of Counseling. USA: Merril Publishing Company.

Richardson, R. (1993). Vivir feliz en familia. Barcelona: Editorial Paidós.

Ronch, J., Van, W. y Stilwell, N. (2006). The Counseling Sourcebook: a practical reference on contemporary issues. New Cork: Crossroad.

Satir, V. (2002). Nuevas relaciones humanas en el núcleo familiar. México: Editorial PAX.

Suares, M. (2002). Mediando en sistemas familiares. Argentina: Paidós.

Umbarger, C. (1999). Terpia Familiar Estructural. Argentina: Amorrortu editores.

Watzlawick, P. y otros. (1983). Teoría de la comunicación humana. Barcelona: Editorial Herder.

Whitaker, C., y Bumberry, W. (1991). Danzando con la familia. España: Ediciones Paidós. 